\title{
INVESTIGATING THE PHYSIOLOGICAL RESPONSES OF THREE ENDAPHIC STRAINS OF CYANOBACTERIA TO CRUDE OIL CONCENTRATIONS IN LIMITED SALINITY AND IRRADIATION CONDITIONS
}

\author{
RAJABNASAB, M. ${ }^{1}-$ KhAVARI-NEJAD, R. A. ${ }^{1 *}-$ ShOKRAVI, S. $^{2}-$ NeJADSATtARI, T. ${ }^{1}$ \\ ${ }^{1}$ Department of Biology, Science and Research Branch, Islamic Azad University, Tehran, Iran \\ ${ }^{2}$ Department of Biology, Gorgan Branch, Islamic Azad University, Gorgan, Iran \\ (phone: +98-912-305-5547) \\ *Corresponding author \\ e-mail: ra.Khavarinejad@gmail.com \\ (Received $7^{\text {th }}$ Feb 2018; accepted $24^{\text {th }}$ May 2018)
}

\begin{abstract}
The objective of the present study is to investigate the physiological responses of three soil strains of cyanobacteria (collected from areas contaminated with oil in southern Iran and from paddyfields in north of Iran) to crude oil concentrations in limited salinity $(\mathrm{NaCl})$ and irradiance conditions. Three cyanobacteria species of Fischerella sp. ISC107, Nostoc sp. ISC101, Phormidium sp. ISC108 were assayed. After purification, samples were grown in BG11 and BG11 0 media. The results showed that the efficiency of hydrocarbon source utilization of Phormidium sp. ISC108 was higher than in other cyanobacteria in crude oil treatment. The highest growth rate was observed at $3 \%$ crude oil concentration in Phormidium sp. ISC108. Also, the highest levels of allophycocyanin, phycocyanin, phycoerythrin, chlorophyll, carbohydrate, protein and phycobiliprotein were obtained from cyanobacteria Phormidium sp. ISC108 had larger phycobilisomes than the other strains $(3.99 \mu \mathrm{g} / \mathrm{gdw})$. The highest ratio of PSII/PSI was observed in Fischerella sp. ISC107. The highest levels of photosynthetic indices were assigned to $3 \%$ crude oil. In fact, reducing photosynthetic efficiency in higher levels of crude oil could be related to the toxic effect of organic hydrocarbons on algae growth. It can be concluded that the cyanobacteria can be used as a bioremediation for decomposing crude oil especially in the coastal area of the Persian Gulf and the Caspian Sea. The results of this research can be valuable for reducing the contamination which affects the fauna and flora of the marine ecosystems in Iran.
\end{abstract}

Keywords: crude oil, cyanobacteria, allophycocyanin, chlorophyll, carbohydrate, phycobiliprotein

Abbreviations: APC: Allophycocyanin; Chl: Chlorophyll; PE: Phycoerythrin; PC: Phycocyanin; PBP: Phycobiliproteins; PSI, PSII: Photosystem I, II; PBP/Chl: PSII/PSI ratio; Phycobilisome size: $\mathrm{PC}+\mathrm{PE} / \mathrm{APC}$

\section{Introduction}

In tropical and temperate crude oil production sites, cyanobacterial mats often develop on petroleum contaminated zones in surface soils and water environments. Cyanobacterial mats are microbial combinations composed of photosynthetic and nonphotosynthetic bacteria and fungi embedded in cyanobacteria mucilage (Shruthi and Rajashekhar, 2014). Factors that influence the uptake, bioconcentration and degradation of many chemical pollutants include extremely limited light, the structure and concentration of the chemical substances, $\mathrm{pH}$, temperature and nutrient availability of the medium, cell size, number and physiological capabilities of microorganisms (Amirlatifi, 2011). Crude oil is a highly toxic mixture of more than 10000 different hydrocarbons. Accidental spills of crude oil in environment cause severe contamination of marine and continental ecosystems. Contamination is an important problem in waters 
due to spill of processed petroleum derivates especially diesel and fuel (Liu et al., 2009). These pollutants can potentially be degraded by a great variety of soil and aquatic microorganisms. Bacteria, filamentous fungi, yeasts, and cyanobacteria are known to be important hydrocarbon degraders (Prince et al., 2010; Das and Chandran, 2011).

In fact, toxicity and transformation of pollutants may change by cyanobacteria or microalgae depending on the species. The strains of microalgae (Stichococcus sp., Chlorella sp. and Scenedesmus quadricauda) and cyanaobacteria (Nostoc sp., and Phormidium sp.) are capable to grow without any apparent toxic effect in medium containing $1 \%$ black oil and bacterial protectants. The bacteria protect the algae from the toxic effect of the oil, while the cyanobacteria provide the bacteria with oxygen $\left(\mathrm{O}_{2}\right)$ and other extracellular carbon-rich exudates (Stal, 1995). For example, El-Sheekh et al. (2013) revealed that the growth of Scenedesmus obliquus was increased in the presence of high concentrations of crude oil as compared with Chlorella vulgaris and the highest growth of Scenedesmus obliquus was obtained at $0.5 \%$ crude oil, whereas, in $C$. vulgaris, the highest rate of growth was obtained at $2 \%$ crude oil. Some metabolic pathways are inhibited or abolished and some others are enhanced or induced when a change in the environment exceeds a certain threshold level. There are certain reports on the responses of cyanobacteria to oil pollution (Abed et al., 2015; Shruthi and Rajashekhar, 2014; Tamkini et al., 2015) regarding the metabolic versatility of cyanobacteria in different strains. For example, Iranian Stigonema strain Fischerella sp. FS 18, showed the best growth at $0.5 \%$ salinity (Soltani et al., 2011) but this may have changed and reached to $1 \%$ at different alkalinity (Amirlatifi et al., unpublished data) and Irradiance (Soltani et al., 2007).

Despite of this high potential of microalgae, there is not much attention to the physiological activities of these microorganisms under petroleum contamination. Recent works are changing and some preconceived notions concerning the adaptation of microalgae to extreme environments. As might be expected, physiological acclimatization is enough to achieve adaptation under slightly stressful conditions (Costas et al., 2008). It seems logical to believe that these versatile organisms may have powerful acclimation and adaptation mechanisms to help them stay in extreme habitats, such as oil-polluted soils for a long time. Crude oil rapidly inhibits photosynthesis and growth of microalgae, but little is known about the mechanisms that allow the adaptation of microalgae to extreme environments.

In order to enhance the knowledge on the adaptation of microalgae, including Cyanobacteria to extreme petroleum contamination (Carrera-Martinez et al., 2011), investigating the ecophysiological behaviors of native organisms under field and laboratory conditions is of priority. Southern and northern epidaphic and endaphic cyanobacteria are unexplored. Despite the fact that the southern provinces are oil-rich regions and oil is strategic for Iran, and given that cyanobacteria have been found to have significant potential in the biotechnology of medicine, industry, fisheries presently, little is known about the ecophysiology of the epidaphic and endaphic cyanobacteria of the oil and gas fields in the south and north of Iran (Soltani et al., 2006).

In this way, the demonstration of these organisms could be the reason for future exploitation from various aspects, including physiology and ecophysiology. As it was noted, given that oil and agriculture are of particular importance in the Iranian economy such studies are considered strategic and also the problem of survival and growth under 
various stress conditions could be useful for applied dimensions considering the necessity of using soil reformers in the future (Soltani et al., 2006).

Combined review of three concentrations of oil; the intensity of limited light can be considered as innovative work in the present study. The microbial stacks and shells should be able to deal with these three factors simultaneously both in flood conditions (rice cultivation) and under the conditions of the underlying layer of oil, and in combination condition. In most studies performed, one or two factors have taken under consideration (Rajendran et al., 2007). However, due to the lack of data for comparison with other indigenous specimens in the country and elsewhere in the world, it is necessary to use reports than detailed scientific analysis (Shokravi et al., 2002).

The objective of present work was to investigate physiological responses of three soil strains of cyanobacteria (collected from areas contaminated with oil in southern Iran and from paddy-fields in north of Iran) to crude oil concentrations in limited salinity and irradiance conditions. The authors hope that, the present work would be an attempt for better understanding of potential native cyanobacteria for both agricultural biotechnological and oil bioremediation projects.

\section{Materials and methods}

\section{Isolation of strains}

Fischerella sp. ISC107, Nostoc SP. ISC101, Phormidium sp. ISC108 were collected from north (paddy-fields of Golestan province, near the Caspian Sea) and south (petroleum contaminated soils near the Persian Gulf) (Fig. 1). The collected samples were cultured by ordinary methods (Lowry et al., 1971). Purification and liquid cultures were performed by solid agar and routine procedures with BG11 and BG11 $1_{0}$ media (Andersen, 2005). $\mathrm{BG} 10_{0}$ was used that included the following ingredients: $\mathrm{MgSO}_{4} \cdot 7 \mathrm{H}_{2} \mathrm{O}, \quad 0.3 \mathrm{mM} ; \quad \mathrm{CaCl}_{2} \cdot 2 \mathrm{H}_{2} \mathrm{O}, \quad 0.25 \mathrm{mM} ; \quad \mathrm{K}_{2} \mathrm{HPO}_{4} \cdot 3 \mathrm{H}_{2} \mathrm{O}, \quad 0.18 \mathrm{mM}$; $\mathrm{Na}_{2} \mathrm{MgEDTA}, 0.003 \mathrm{mM}$, citrate ferric $0.02 \mathrm{mM}$; citric acid, $0.029 \mathrm{mM} ; \mathrm{Na}_{2} \mathrm{CO}_{3} 0.188$ $\mathrm{mM}$; microelements $1 \mathrm{ml} \cdot \mathrm{L}^{-1}$. All chemical materials were purchased from Merck Company (Germany) and used without further purification.

\section{Culture conditions}

Stock cultures were grown in the BG11, and BG11 culture media. Each cyanobacterium was pre-cultured in Erlenmeyer flasks at $\mathrm{pH} 7$ and at temperature of 25 ${ }^{\circ} \mathrm{C}$. Cells were collected from stock cultures in logarithmic phase of growth and were used as inoculate for experiments. Cells from stock culture were inoculated in $300 \mathrm{ml}$ of BG1 $11_{0}$ medium in $500 \mathrm{ml}$ Erlenmeyer flasks stoppered with cotton plugs. The following treatments were used: 0 (control), 1, 2, 3, 4, 5, 6, 7, 8, 9 and 10\% crude oil and limited irradiation $\left(5 \mu \mathrm{Em}^{-2} \mathrm{~s}^{-1}\right)$ and limited salt $(17 \mathrm{mM} \mathrm{NaCl})$ for incubation period of 14 days.

\section{Analytical methods}

\section{Growth measurements and pigment composition}

Cell growth was checked by evaluation of algal dry weight, every 2 days in duplicate (Kaushik, 1987; Shruthi and Rajashekhar, 2014). Chlorophyll $a$ (Chl. $a$ ) concentration was evaluated performing overnight extractions with methanol. Centrifuged extracts were measured at $665 \mathrm{~nm}$ and calculated by the extinction coefficient (Lowry et al., 
1951). Phycobiliproteins were extracted after osmotic shock and evaluated spectrophotometrically at 750, 652, 615 and $562 \mathrm{~nm}$. Oxygen $\left(\mathrm{O}_{2}\right)$ evolution was measured using a Clark-type sensors measuring oxygen partial pressure from Hach Chemical Company (Shruthi and Rajashekhar, 2014). The total carbohydrates were measured using the anthrone-thiourea method (Herbert et al., 2010), and soluble proteins were estimated using bovine serum albumin as the standard (Liu et al., 2009).

\section{Statistical analysis}

Statistical differences were examined using the General linear multivariate model test by SPSS software version 16.0.

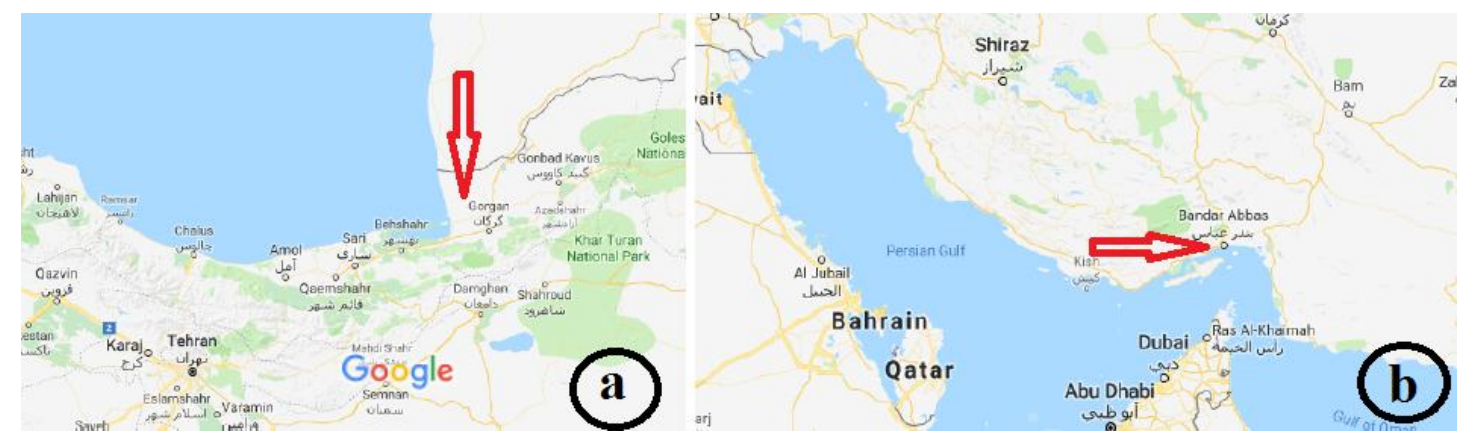

Figure 1. The sampling location: a) North of Iran (paddy-fields of Golestan province, near the Caspian Sea) and b) South of Iran (petroleum contaminated soils near the Persian Gulf

\section{Result and discussion}

Cyanobacteria isolated from northern paddy-fields and southern oil fields of Iran include Fischerella sp. ISC107, Nostoc sp. ISC101, Phormidium sp. ISC108. The results of the physiological responses of isolated samples to the increase of crude oil in limited light and limited salinity conditions were $5 \mu \mathrm{E} \cdot \mathrm{m}^{-2} \cdot \mathrm{s}^{-1}$ and $17 \mathrm{mM}$, respectively $(\mathrm{p}<0.01)$.

Table 1 shows the growth rate $(\mu)$, the doubling time $(\mathrm{G})$ in the three samples under oil treatments from zero to $10 \%$. As it is shown, growth rate and doubling time was positive for all three samples. Investigating the doubling time indicated that the highest amount of time to be doubled was observed in the control concentrations for Phormidium sp. ISC108, 1 and 6\% for Fischerella sp. ISC107 and 4\% for Nostoc sp. ISC101. On the other hand, the growth rate in Fischerella sp. ISC107 and Nostoc sp. ISC101 showed an increasing trend from zero to $10 \%$ of crude oil, while a different process was observed in Phormidium sp. ISC108, so that the highest rate of growth increased to $3 \%$ concentration, and with increasing concentrations up to $4 \%$, where reduction in growth rates was observed $(\mathrm{p}<0.01)$. Sample survival in oil treatments indicates that the sample could not increase the biomass in the treatments and only retained itself from death, and again, increasing trend was observed to $6 \%$ concentration, then, a decreasing trend was observed with increasing concentrations up to $10 \%$ (Table 1) ( $\mathrm{p}<0.01)$. Kiayi et al. (2013) found that the time of cell division, and hence, the doubling time was decreased with the increase in growth, the results are consistent with the obtained results in this paper (Kaushik, 1987). 


$$
-4563 \text { - }
$$

Table 1. Specific growth rate $(\mu)$ and doubling times $(G)$ of three cyanobacteria strains in limited light and limited salinity conditions were $5 \mu \mathrm{E} \cdot \mathrm{m}^{-2} \cdot \mathrm{s}^{-1}$ and $17 \mathrm{mM}$

\begin{tabular}{|c|c|c|c|c|c|c|c|c|c|c|c|c|}
\hline \multirow{2}{*}{ SP } & \multicolumn{12}{|c|}{ Oil percentage (\%) } \\
\hline & & $\mathbf{0}$ & 1 & 2 & 3 & 4 & 5 & 6 & 7 & 8 & 9 & 10 \\
\hline \multirow{2}{*}{$\begin{array}{c}\text { Phormidium SP. } \\
\text { ISC108 }\end{array}$} & $\mathrm{G}$ & 1.73 & 0.62 & 0.68 & 0.66 & 0.86 & 1 & 0.84 & 0.93 & 0.99 & 0.96 & 1.19 \\
\hline & $\mu$ & 0.4 & 1.1 & 1.02 & 1.04 & 0.8 & 0.69 & 0.82 & 0.74 & 0.7 & 0.72 & 0.58 \\
\hline \multirow{2}{*}{$\begin{array}{c}\text { Fischerella SP. } \\
\text { ISC107 }\end{array}$} & G & 1.31 & 1.74 & 0.94 & 1.12 & 1.02 & 1.37 & 1.74 & 1.57 & 1.42 & 0.9 & 0.92 \\
\hline & $\mu$ & 0.52 & 0.39 & 0.73 & 0.61 & 0.67 & 0.5 & 0.39 & 0.44 & 0.48 & 0.76 & 0.75 \\
\hline \multirow{2}{*}{$\begin{array}{l}\text { Nostoc SP. } \\
\text { ISCIOI }\end{array}$} & G & 1.37 & 0.82 & 0.94 & 0.99 & 1.18 & 1.06 & 1.02 & 0.79 & 0.82 & 0.95 & 0.66 \\
\hline & $\mu$ & 0.5 & 0.83 & 0.73 & 0.69 & 0.58 & 0.65 & 0.67 & 0.86 & 0.83 & 0.72 & 1.03 \\
\hline
\end{tabular}

Figure 2 presents the growth curve of three samples under crude oil treatment. As it is the logarithmic phase of Phormidium sp. ISC108 an increasing trend ( $p<0.01)$ was observed. This trend was observed in all treatments in this sample. The samples showed a decrease in growth after the ninth day until the thirteenth day $(\mathrm{p}<0.01)$. In addition, the absorption rate in this curve was higher than those of the other two samples.

The results indicated the survival of the Phormidium sp. ISC108 in all oil treatments. Also an upward trend was observed in the study of the logarithmic phase of Fischerella sp. ISC107 and Nostoc sp. ISC101 strains. So, in different concentrations of crude oil treatment, they first encountered a decline in growth rate and again showed an increasing trend $(\mathrm{p}<0.01)$. Generally, the productivity of the hydrocarbon resource of Phormidium sp. ISC108 was higher than those of other strains in crude oil treatment (Fig. 2a, b, c). Amirlatifi et al. (2013) reported that biomass amounts was 3.88, 4.35 and $4.60 \mathrm{mg} / \mathrm{ml}^{-1}$ on the $12^{\text {th }}$ day of inoculation at control, 1 and $7 \%$ concentrations, respectively. This increasing trend was consistent with the results of this study.

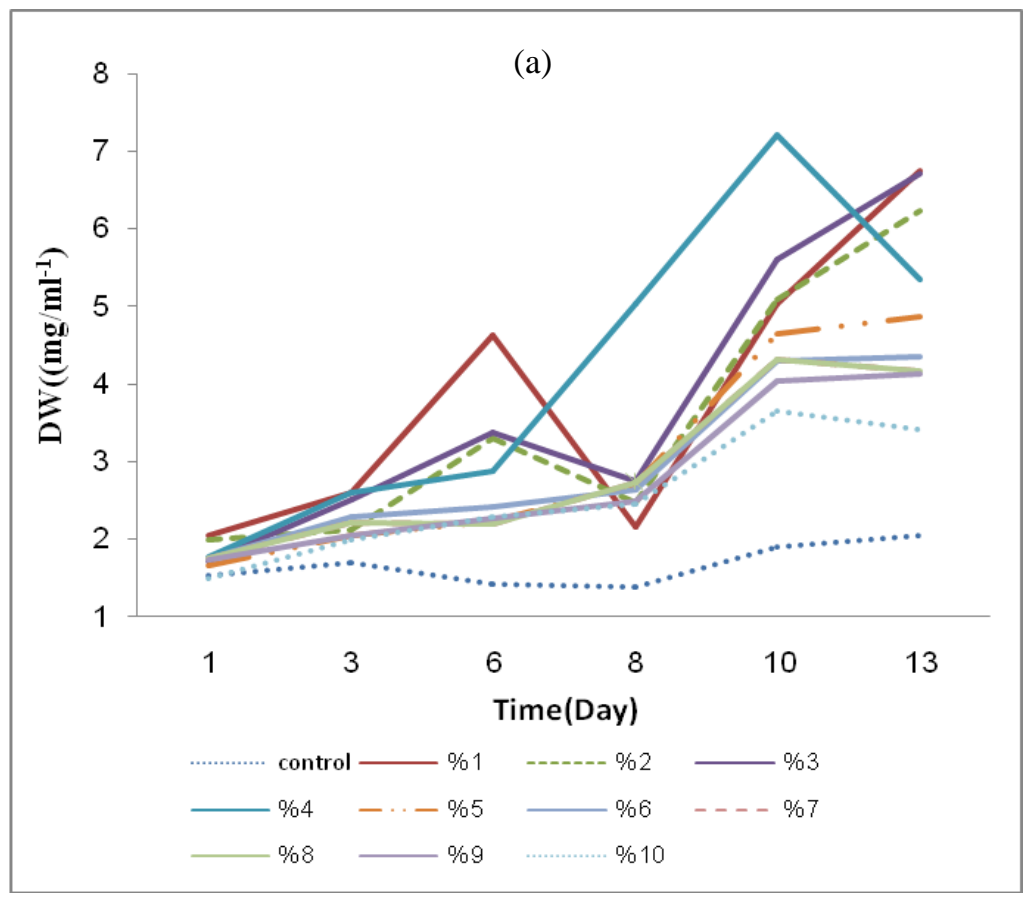




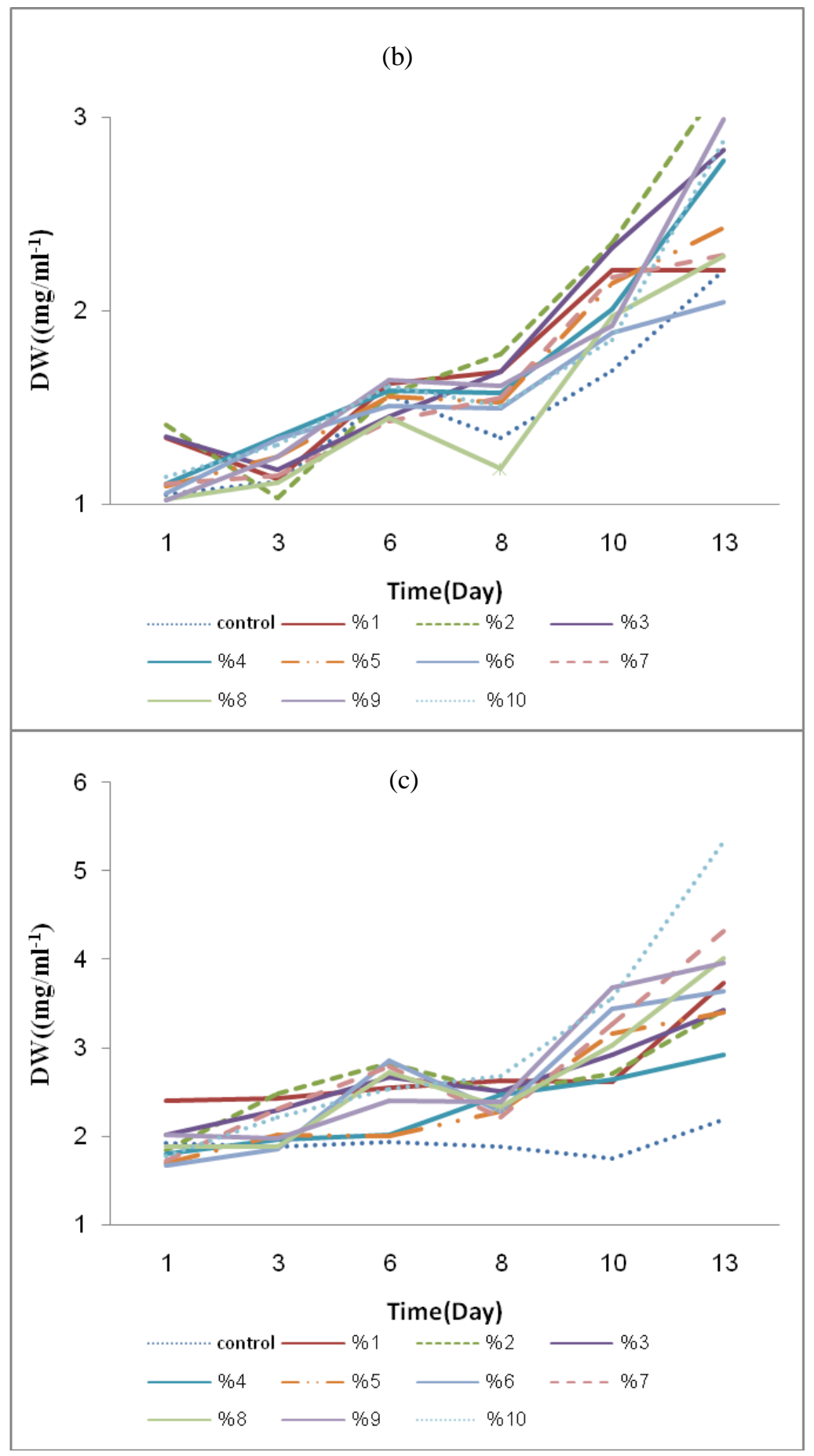

Figure 2. Dry weight $(D W)$ in different crude oil concentrations. limited light and limited salinity conditions were $5 \mu \mathrm{E} \cdot \mathrm{m}^{-2} \cdot \mathrm{s}^{-1}$ and $17 \mathrm{mM}$. (a) Phormidium SP. ISC108; (b) Fischerella SP. ISC107; (c) Nostoc SP. ISC101

Figure 2 shows that in cyanobacteria Phormidium sp. ISC108; lag phase is not observed throughout the treatments with different oil levels. The progressive phase with a roughly identical gradient was observed in the first days after inoculation, which results from the rapid adhesion of the sample to the environment. On the third day, and 
after the seventh day of inoculation, the growth rate changes and the effect of oil treatments could be observed.

Growth up to $1.04 \mathrm{mg} / \mathrm{ml}^{-1}$ is due to the high uptake of this sample (in general) with high concentrations of crude oil. This growth is reduced in two other cyanobacteria (Fig. 2a, c). In Fischerella sp. ISC107, although a decline was observed in growth rate, generally due to habituation to oil change conditions was more sensible in the first days after inoculation (Fig. 2b). The pattern of behavior in this cyanobacterium is due to the absence of a negative growth phase until the third day at a concentration of $3 \%$ of the specific crude oil. However, a sample under the influence of time could be adapted to this concentration (Fig. 2b). The existence of a long-term delayed phase in salinity of $3 \%$ in cyanobacterium Nostoc sp. ISC101 is remarkable, which continues even as negative growth until the eighth day.

In addition, in this sample, the lower level was observed in the treatments except at $10 \%$ with high growth slope as the same as Phormidium, but latent and negative phase is more remarkable, which generally is due to the incapability to habituate in short time (less than $72 \mathrm{~h}$ ) to high concentrations of oil (Fig. 2c). The shorter lag phase and the same trends of growth curves that can be observed in other samples showed that Phormidium is not sensitive to higher concentration of oil through the more growth and will not be affected in the short time.

On the contrast, the growth rate in Table 1 indicates that the amount of produced biomass in such a situation is higher than those of other treatments (Table 1). The effect of oil concentration on all three samples is considerable and the amount of biomass production in cyanobacteria is affected by combination of oil concentrations, irradiation and salinity stresses (Table 1). The results of mean comparisons using Tukey's test shows that dry weight in different genera under crude oil was classified into three groups and the genus Phormidium sp. ISC108 and Fischerella sp. ISC107 had the highest and the lowest amount (Table 2).

Table 2. Dry weight $(D W)$ in three strains of cyanobacteria under limited light and limited salinity conditions were $5 \mu E \cdot \mathrm{m}^{-2} \cdot \mathrm{s}^{-1}$ and $17 \mathrm{mM}$. Data shows $X \pm S E$

\begin{tabular}{c|c}
\hline SP & DW $\left(\mathbf{m g} / \mathbf{m l}^{\mathbf{1}}\right)$ \\
\hline Phormidium SP. ISC108 & $3.23 \pm 1.628^{\mathrm{a}}$ \\
Fischerella SP. ISC107 & $1.67 \pm .543^{\mathrm{c}}$ \\
Nostoc SP. ISC101 & $2.58 \pm .737^{\mathrm{b}}$ \\
\hline
\end{tabular}

The amounts of dry weight in different days also shows a significant difference, so that the values were classified into 5 categories, the highest and the lowest amounts of dry weights were observed on day 13 and the first day, respectively (Table 3). On the other hand, the dry weight contents at different concentrations of crude oil were classified into three categories, which showed a significant difference, so that the control concentration had the lowest value and concentrations of 1-5\% crude oil shows the highest amount (Table 4). Dhull et al. (2014) found that by increasing the concentration of carbon in the medium, the biomass production rate increases in some microalgae species, which is consistent with the results of this study.

Lack of salinity or salinity of $17 \mathrm{mM}$, could affect the results. The same amount of salinity and the lack of involvement in such surveys is a defect for any process with a biotechnological approach. Gu et al. (2012) shows that the growth and production of 
pigments in Nannochloropsis oculata under pond conditions and using in vitro photobioreactor is affected by salinity. The salinity range was from 15 to $55 \mathrm{~g} / \mathrm{l}^{-1}$ in the form of five treatments. Reducing salinity from 55 to $15 \mathrm{~g} / \mathrm{l}$ leads to increasing growth and chlorophyll content. Lack of lag phase in the presence of high concentrations of oil, could be considered. In the studies of Amirlatifi et al. (2011) and Abed et al. (2015), the absence of lag phase has been evaluated from the viewpoint of the outflow of wallforming compounds and nitrogen metabolism.

Table 3. Dry weight $(D W)$ in different days under limited light and limited salinity conditions were $5 \mu \mathrm{E} \cdot \mathrm{m}^{-2} \cdot \mathrm{s}^{-1}$ and $17 \mathrm{mM}$. Data shows $X \pm S E$

\begin{tabular}{c|c}
\hline Time(Days) & DW $\left(\mathbf{m g} / \mathbf{m l}^{\mathbf{1}}\right)$ \\
\hline 1 & $1.60 \pm .370^{\mathrm{e}}$ \\
3 & $1.84 \pm .511^{\mathrm{d}}$ \\
7 & $2.23 \pm .721^{\mathrm{c}}$ \\
9 & $2.27 \pm .886^{\mathrm{c}}$ \\
11 & $3.30 \pm 1.531^{\mathrm{b}}$ \\
13 & $3.72 \pm 1.382^{\mathrm{a}}$ \\
\hline
\end{tabular}

Table 4. Dry weight $(D W)$ in different crude oil concentrations under limited light and limited salinity conditions were $5 \mu E \cdot \mathrm{m}^{-2} \cdot \mathrm{s}^{-1}$ and $17 \mathrm{mM}$. Data shows $X \pm S E$

\begin{tabular}{c|c}
\hline Crude oil $(\%)$ & DW $\left(\mathbf{m g} / \mathbf{m l}^{\mathbf{- 1}}\right)$ \\
\hline 0 & $1.69 \pm .341^{\mathrm{c}}$ \\
1 & $2.76 \pm 1.42^{\mathrm{a}}$ \\
2 & $2.68 \pm 1.258^{\mathrm{a}}$ \\
3 & $2.74 \pm 1.394^{\mathrm{a}}$ \\
4 & $2.73 \pm 1.769^{\mathrm{a}}$ \\
5 & $2.72 \pm 1.588^{\mathrm{a}}$ \\
6 & $2.40 \pm 1.091^{\mathrm{b}}$ \\
7 & $2.44 \pm 1.01^{\mathrm{b}}$ \\
8 & $2.34 \pm .991^{\mathrm{b}}$ \\
9 & $2.41 \pm .950^{\mathrm{b}}$ \\
10 & $2.42 \pm 1.039^{\mathrm{b}}$ \\
\hline
\end{tabular}

A sample that can be adapted to the new conditions at the first days after inoculation will not have problem with wall-forming compounds and subsequent reproduction for entry into the log phase (Soltani et al., 2011). Under laboratory conditions, cyanobacteria have shown a delayed phase or a negative growth phase depending on the acidity and alkalinity conditions (Amirlatifi, 2011).

Shokravi et al. (2002) reported that the Fischerella sp., Nostoc sp. and Oscillatorian cyanobacteria have shown a lag phase when they enter the natural environment due to their incompatibility with the environment in the first days. It should not be said which factors have contributed to the difference in growth behavior, but this difference has always been existed. 
Compared with the laboratory conditions employed in the present work, as well as studies by Amirlatifi et al. (2011), Pakzad et al. (2011) and Badeli et al. (2012), although neither of the three environments has shown significant differences in terms of growth on the twelfth day, under laboratory conditions, this behavior is not observed at least within the first few days. It was not possible to follow the growth curve in the days following the twelfth day, and it is possible that the cyanobacteria would be retrieved, but it cannot be commented on this due to the lack of investigation on this issue.

Under laboratory conditions, the behavior of samples is different, and the progressive and stagnant phase continues until the $12^{\text {th }}$ day. This indicates the difference between the behaviors of the natural, and, the laboratory environments. In the studies of Chekigar et al. (2012) and Marvizade (2012) on cyanobacterium Microchaete sp. it has been shown that cyanobacteria changes trend in carbon dioxide and salinity treatments in the last days and shows a pattern similar to that in the natural conditions in this study.

In this study, such a pattern was related to the change in photosynthetic mechanism (Marker, 1972) and the carbon dioxide condensation mechanism (Chekigar, 2012) under laboratory conditions. It is likely that such a situation exists in the natural environment, as well. Particularly, under the natural environment, there was no carbon dioxide inoculation. However, it is definitely not possible to comment because the condensation-inhibiting compounds were not used in this study.

Table 5 deals with the effect of oil concentrations on the ability of cyanobacteria to habituate with limited light. Regarding the severity of extreme limited light, surveys conducted in Iran have been limited to surveys devoted to paddy-field of Northern Province in Iran.

Table 5. Photosynthetic pigments amount in different cyanobacteria grown under limited light and limited salinity conditions were $5 \mu E \cdot \mathrm{m}^{-2} \cdot \mathrm{s}^{-1}$ and $17 \mathrm{mM}$. Data shows $X \pm S E$

\begin{tabular}{c|c|c|c|c|c|c|c|c|c|c}
\hline SP & APC & PC & PE & Chl & Carbo & Pro & PBP & PC+PE/APC & PBP/Chl \\
\hline & \multicolumn{7}{|c|}{$\left(\boldsymbol{\mu g} / \mathbf{g}^{-1} \mathbf{d w}\right)$} \\
\hline $\begin{array}{c}\text { Phormidium SP. } \\
\text { ISC108 }\end{array}$ & $4.79 \pm 4.59^{\mathrm{a}}$ & $10.62 \pm 7.14^{\mathrm{a}}$ & $8.48 \pm 2.51^{\mathrm{a}}$ & $4.26 \pm .23704^{\mathrm{a}}$ & $633.60 \pm 2.38^{\mathrm{a}}$ & $677.10 \pm 3.93^{\mathrm{a}}$ & $23.89 \pm 1.30 \mathrm{E} 1^{\mathrm{a}}$ & $3.99 \pm 1.21^{\mathrm{a}}$ & $5.60 \pm 0.75^{\mathrm{c}}$ \\
$\begin{array}{c}\text { Fischerella SP. } \\
\text { ISC107 } \\
\begin{array}{c}\text { Nostoc SP. } \\
\text { ISC101 }\end{array}\end{array}$ & $3.24 \pm 1.59^{\mathrm{b}}$ & $4.60 \pm 2.04^{\mathrm{c}}$ & $4.79 \pm 1.90^{\mathrm{c}}$ & $1.03 \pm .09844^{\mathrm{c}}$ & $281.40 \pm 2.12^{\mathrm{c}}$ & $344.70 \pm 1.16^{\mathrm{c}}$ & $12.63 \pm 4.07^{\mathrm{c}}$ & $1.69 \pm 3.32^{\mathrm{b}}$ & $12.26 \pm 1.35^{\mathrm{a}}$ \\
\hline
\end{tabular}

APC: Allophycocyanin, PE: Phycoerythrin, PC: Phycocyanin, Carbo: Carbohydrate, Pro: Protein,Chl: Chlorophyll, PBP: Phycobiliproteins

The results of the mean comparisons obtained from the physiological traits with Tukey's test shows that PC (Phycocyanin), PE (Phycoerythrin), Chl (Chlorophyll), Carbo (Carbohydrate), Pro (Protein) and PBP (Phycobiliproteins) traits were classified into three groups in different genus, so that the genus Phormidium sp. ISC108 had the highest and Fischerella sp. ISC107 had the lowest amount. Also, evaluation APC (Allophycocyanin) values showed that the genus Fischerella sp. ISC107 showed the lowest amount but other genus show the highest amount.

The study of PBP/Chl and PC+PE/APC values showed that the concentration of $10 \%$ crude oil was the highest value (Table 6). In fact, the ratio of $\mathrm{PBP} / \mathrm{Chl}$ shows the relationship between the photosystem II and the photosystem I. It should be noted that these results were precisely the same as that found for the comparison of the mean values of $\mathrm{PBP} / \mathrm{Chl}$ (PSII/PSI ratio). Also, the results of the measurement of phycobilisome (PC+PE/APC) showed that the Phormidium sp. ISC108 strain had the 
highest value (3.99; $\mathrm{P} \leq 0.01)$. On the other hand, $\mathrm{PBP}$ values were classified into three categories, as Fischerella sp. ISC107 showed the minimum amount but Phormidium sp. ISC108 showed the maximum amount (Table 5).

Table 6. Photosynthetic pigments amount in different crude oil concentrations under limited light and limited salinity conditions were $5 \mu E \cdot \mathrm{m}^{-2} \cdot \mathrm{s}^{-1}$ and $17 \mathrm{mM}$. Data shows $X \pm S E$

\begin{tabular}{|c|c|c|c|c|c|c|c|c|c|}
\hline $\begin{array}{c}\text { Range of } \\
\text { crude oil } \\
(\%)\end{array}$ & APC & PC & PE & Chl & Carbo & Pro & PBP & $\mathrm{PC}+\mathrm{PE} / \mathrm{APC}$ & PBP/Chl \\
\hline & \multicolumn{9}{|c|}{$\left(\mu \mathrm{g} / \mathrm{g}^{-1} \mathrm{dw}\right)$} \\
\hline 0 & $4.62 \pm 2.84^{\mathrm{b}}$ & $6.76 \pm 4.27^{\mathrm{bcd}}$ & $6.07 \pm 2.30^{\mathrm{cd}}$ & $3.38 \pm 0.10^{\mathrm{ab}}$ & $463.78 \pm 27.82^{\mathrm{c}}$ & $442.31 \pm 18.15^{\mathrm{f}}$ & $17.09 \pm 1.27 \mathrm{E} 1^{\mathrm{de}}$ & $2.77 \pm 6.044^{\mathrm{bc}}$ & $5.06 \pm 10.59^{\mathrm{b}}$ \\
\hline 1 & $3.93 \pm 3.95^{\mathrm{bc}}$ & $6.70 \pm 4.20^{\mathrm{bcd}}$ & $6.43 \pm 3.41^{\mathrm{bc}}$ & $2.86 \pm 0.23^{\mathrm{c}}$ & $501.00 \pm 21.96^{\mathrm{bc}}$ & $528.81 \pm 4.10^{\mathrm{bc}}$ & $17.97 \pm 1.01 \mathrm{E} 1^{\mathrm{d}}$ & $6.23 \pm 17.15^{\mathrm{b}}$ & $6.28 \pm 9.78^{b}$ \\
\hline 2 & $3.33 \pm 1.64^{\mathrm{c}}$ & $6.18 \pm 3.38^{\mathrm{d}}$ & $6.17 \pm 2.76^{\mathrm{c}}$ & $2.42 \pm 0.17^{\mathrm{d}}$ & $384.12 \pm .19 .37^{\mathrm{cd}}$ & $357.62 \pm 15.22^{\mathrm{g}}$ & $15.25 \pm 7.90^{\mathrm{e}}$ & $3.33 \pm 5.31^{\mathrm{bc}}$ & $6.30 \pm 4.85^{\mathrm{b}}$ \\
\hline 3 & $5.94 \pm 4.16^{\mathrm{a}}$ & $12.94 \pm 8.58^{\mathrm{a}}$ & $9.61 \pm 1.52^{\mathrm{a}}$ & $3.58 \pm 0.3541^{\mathrm{a}}$ & $742.50 \pm 30.32^{\mathrm{a}}$ & $884.62 \pm 52.07^{\mathrm{a}}$ & $28.49 \pm 9.11^{\mathrm{a}}$ & $3.79 \pm 0.71^{\mathrm{bc}}$ & $7.96 \pm 8.99^{\mathrm{b}}$ \\
\hline 4 & $3.79 \pm 2.82^{\mathrm{bc}}$ & $6.57 \pm 3.75^{\mathrm{cd}}$ & $6.13 \pm 2.28^{\mathrm{b}}$ & $2.03 \pm 0.12^{\mathrm{d}}$ & $405.22 \pm 22.52^{\mathrm{d}}$ & $349.55 \pm 19.52^{\mathrm{g}}$ & $16.38 \pm 8.29^{\mathrm{e}}$ & $2.62 \pm 5.77^{\mathrm{bc}}$ & $8.06 \pm 5.96^{\mathrm{b}}$ \\
\hline 5 & $4.20 \pm 3.46^{\mathrm{bc}}$ & $7.09 \pm 4.74^{\mathrm{bcd}}$ & $6.82 \pm 3.00^{\mathrm{b}}$ & $3.36 \pm 0.32^{\mathrm{ab}}$ & $465.46 \pm 26.95^{\mathrm{c}}$ & $449.72 \pm 20.55^{\mathrm{ef}}$ & $18.65 \pm 1.05 \mathrm{E} 1^{\mathrm{b}}$ & $4.48 \pm 13.80^{\mathrm{b}}$ & $5.55 \pm 1.922^{\mathrm{b}}$ \\
\hline 6 & $4.71 \pm 3.64^{\mathrm{b}}$ & $6.90 \pm 5.21^{\mathrm{bcd}}$ & $6.29 \pm 2.54^{\mathrm{bc}}$ & $2.83 \pm 0.18^{\mathrm{c}}$ & $533.27 \pm 28.24^{\mathrm{b}}$ & $530.52 \pm 25.67^{\mathrm{bc}}$ & $18.21 \pm 1.06 \mathrm{E} 1^{\mathrm{c}}$ & $1.22 \pm 0.88^{\mathrm{c}}$ & $6.43 \pm 4.95^{\mathrm{b}}$ \\
\hline 7 & $4.20 \pm 2.63^{\mathrm{bc}}$ & $7.63 \pm 4.18^{\mathrm{bc}}$ & $6.39 \pm 2.36^{\mathrm{bc}}$ & $3.08 \pm 0.24^{\mathrm{c}}$ & $538.71 \pm 29.13^{\mathrm{b}}$ & $552.83 \pm 19.36^{\mathrm{b}}$ & $18.22 \pm 9.56^{\mathrm{bc}}$ & $3.34 \pm 229.32^{\mathrm{bc}}$ & $5.91 \pm 5.64^{\mathrm{b}}$ \\
\hline 8 & $4.19 \pm 2.81^{\mathrm{bc}}$ & $7.88 \pm 6.32^{\mathrm{b}}$ & $6.37 \pm 2.12^{\mathrm{bc}}$ & $2.13 \pm 0.09^{\mathrm{d}}$ & $428.92 \pm 28.82^{\mathrm{de}}$ & $480.81 \pm 20.84^{\mathrm{de}}$ & $18.08 \pm 1.12 \mathrm{E} 1^{\mathrm{cd}}$ & $2.40 \pm 4.01^{\mathrm{bc}}$ & $8.49 \pm 10.80^{\mathrm{b}}$ \\
\hline 9 & $3.60 \pm 2.25^{\mathrm{c}}$ & $7.40 \pm 3.78^{\mathrm{bcd}}$ & $5.54 \pm 0.97^{\mathrm{d}}$ & $1.58 \pm 0.06^{\mathrm{e}}$ & $423.53 \pm 23.57^{\mathrm{de}}$ & $513.13 \pm 23.94^{\mathrm{cd}}$ & $16.11 \pm 6.61^{\mathrm{e}}$ & $3.22 \pm 5.37^{\mathrm{bc}}$ & $10.19 \pm 8.98^{\mathrm{b}}$ \\
\hline 10 & $3.60 \pm 2.05^{\mathrm{c}}$ & $6.78 \pm 2.75^{\mathrm{bcd}}$ & $6.18 \pm 1.82^{\mathrm{b}}$ & $1.40 \pm 0.08^{\mathrm{e}}$ & $324.01 \pm 15.73^{\mathrm{d}}$ & $353.49 \pm 19.37^{\mathrm{g}}$ & $16.12 \pm 6.02^{\mathrm{e}}$ & $8.77 \pm 25.52^{\mathrm{a}}$ & $11.51 \pm 15.01^{\mathrm{a}}$ \\
\hline
\end{tabular}

APC: Allophycocyanin, PE: Phycoerythrin, PC: Phycocyanin, Carbo: Carbohydrate, Pro: Protein, Chl: Chlorophyll, PBP: Phycobiliproteins

Shokravi and Soltani (2011) studied the simultaneous effect of extremely limited light of 2 micromoles quanta per square meter per second and $\mathrm{pH}$ was studied on cyanobacteria Hapalosiphon sp. FS56. Soltani et al. (2006) studies on Fischerella sp. FS 18 showed that this species not only has the ability to survive in this intensity, but also has high photosynthetic and high nitrogen activity. The studies by Amirlatifi et al. (2013) has confirmed the same result for the Nostoc sp. FS 76 and Anabaena sp. FS 77.

The results of the mean comparison of physiological traits using Tukey's test showed in different concentrations of crude oil that the various amounts of APC in different concentrations of oil ( 0 to $10 \%$ ) were classified in 3 groups. Moreover, the lowest amount of APC was observed in 3\% crude oil and the highest amount was obtained in 2, 9 and $10 \%$ concentration of crude oil. While in PC amounts, the lowest values were observed at $2 \%$ crude oil concentration and the highest values were at $3 \%$ crude oil, which were classified in four separate categories. The study of PE values also showed that a sample of $9 \%$ and $3 \%$ oil content had the lowest and the highest value, respectively.

In a study by Hamouda et al. (2016), it was recorded that with the increase in crude oil content, the amount of carotenoides was increased in Calothrix. kesseleri and Anabaena oryzae, while according to Liu et al. (2009), the amount of carotenoids was decreased in mixotrophic cells than photo-autotrophic cells, which may be due to the toxic effect of organic hydrocarbons on the growth of algae, which is consistent with the results of this study and with the results of Liu et al. (2009). Also, the results of Chl values in various oil concentrations show that concentrations of 9 and $10 \%$ were the lowest and the concentrations of $3 \%$ were the highest amounts and the data were categorized in five separate categories. 
El-Sheekh et al. (2013) reported that the highest amount of chlorophyll $(6.13 \mu \mathrm{g}$ $\mathrm{ml}^{-1}$ ) was obtained in Chlorella vulgaris fifteen days after inoculation with $1.5 \%$ concentration of crude oil, while in the samples examined in the present study, the highest amount $(3.58 \mu \mathrm{g} / \mathrm{gdw} ; \mathrm{P} \leq 0.01)$ was obtained at a concentration of $3 \%$ crude oil.

The obtained results from Carbo values indicated that the values were classified into 7 categories, so that a concentration of $10 \%$ crude oil and a concentration of $3 \%$ crude oil had the lowest and the highest values, respectively. In the following, the physiological traits showed that the protein traits were classified into 7 groups, as the concentration of $10 \%$ and $3 \%$ showed the lowest and the highest values, respectively.

By investigating PBP values, it was concluded that the concentration of $3 \%$ crude oil was the highest and the concentrations of 2, 9 and $10 \%$ crude oil contained the lowest values, so that the data were categorized into five categories. Amirlatifi et al. (2013) found that the concentration of photosynthetic pigments depends on the concentration of crude oil that by increasing crude oil concentration, phycobiliproteins concentration was reduced. The results of the present study are also consistent with the mentioned study.

It seems that the reason for the reduction of phycobiliproteins in algae under conditions of environmental stress is resulted from the induction of biosynthesis of certain proteins. It can also affect the stability of the protein and its re-rotation by the protein proteolytic rate.

Pittmanet al. (2010) reported that the optical intensity limited to $10 \mu \mathrm{m}$ quanta per square meter per second has been used on the cyanobacteria Nostoc sp. UAM206 and has reduced the growth and photosynthesis activity in comparison with $60 \mu \mathrm{M}$ Quanta per square meter per second and $300 \mu \mathrm{M}$ quanta per square meter per second, respectively.

Studies by Marvizade (2012) and Chekigar et al. (2012) have shown that the two species studied in this article retain their survival and have high photosynthetic and nitrogen activity in extreme conditions of $2 \mu \mathrm{M} \mathrm{Em}^{-2} \mathrm{~s}^{-1}$ in the presence of white light, which is far lower than other tested species such as Nostocsp FS 76 and Anabaena sp. FS 77 (Amirlatifi, 2011; Badeli et al., 2012).

Table 5 and the results table of photosynthesis (Table 6) show that the application of oil concentration not only does not entail tension on the photosynthetic apparatus, but also significantly increased the efficiency of this apparatus $(\mathrm{p}<0.01)$. The maximum rate of photosynthesis increases significantly in these conditions $(\mathrm{p}<0.01)$. This issue is in full compliance with the increase in sample growth rate under the above conditions.

Measurements of photosynthetic pigments (Tables 5 and 6 ) are due to phycobilisome system. It seems that in addition to the main pigments, the rode sections and the core sections of the phycobilisome is oscillated under the influence of oil concentrations.

It seems that the increase in oil concentration has significant effect on the increase of light absorption power $(\mathrm{p}<0.01)$. In addition, salinity not only does not damage the phycobilisome system, but also adds to the length and power of its optical absorption. This is a major biotechnological achievement that could be particularly used in the process of inoculation of algae, for agricultural and for other purposes. Whether nonaeration (although it reduces the activity of the phycobilisome system a little) increases the limited light absorption efficiency and amplifies it through the phycobilisomes is another biotechnological achievement that can be useful in intensive culture through eliminating of carbon dioxide induction (Montagnolli et al., 2015; Prince et al., 2010). 
Significant increase in total sugar and total protein content (Tables 5 and 6 ) is remarkable from two perspectives $(p<0.01)$. Coordination with the potential of photosynthesis and nitrogen activation on the one hand, and the efficiency of the phycobilisome system on the other, is shown to be capable of generating total carbohydrate and protein. In other words, salinity not only does not reduce the level of carbohydrate pool and protein, but also significantly increases it $(\mathrm{p}<0.01)$.

Relative absorption studies under in vivo conditions could be considered as evidence of the situation of the pigmentation of the reaction center structures, the light collector complex and phycobilisome antennas (qualitatively).

It seems that the phycocyanin level is interacted with the growth rate observed in both cyanobacteria, as the main and permanent barrier of phycobilisome in both cyanobacteria, under the influence of extreme limited light and salinity, although the absorption peaks in cyanobacteria are moved a little affected by combined stresses.

Soltani et al (2007) stated that cyanobacteria Fischerella sp. FS 18 loses its central allophycocyanin under acidity and alkalinity treatments and changes in light intensity.

Shokravi et al. (2011) in their research declared that Cyanobacteria Hapalosiphon sp.FS56 loses its allophycocyanin part under combined treatments of limited extreme light, acidity and alkalinity, in extreme alkaline conditions. Both samples contain phycoerythrin parts. Ahmadi Livani et al. (2009) reported that salinity and limited irradiation treatments in cyanobacterium Hapalosiphon sp. FS56 have not removed the allophycocyanin.

However, the results of this study indicate that the content of phycobilisome is completely preserved in extreme light stress conditions ( 2 micromoles quanta per square meter/second) and salinity in both cyanobacteria. In the studies of Tamkini et al. (2015), it has been shown for the first time that short-term irradiation and carbon dioxide treatments could lead to the displacement of pigments. This finding was also used in this study. It appears that the physiological fluidity of the sample in short periods of time (in shock) at very low light intensities can be as high as $2 \mu \mathrm{M} \mathrm{Em}^{-2} \mathrm{~s}^{-1}$. The results of Tamkini et al. (2015) showed that optical shock and carbon dioxide could lead to extreme reactions.

In addition to this, the combination of crude oil, light and carbon dioxide shocks can change the color of the pigment and, of course, the size of the phycobilisome, even in the five to ten minute period. This is also compatible in other light intensities.It is appeared that light and carbon dioxide, combined with salinity affect the state of lightabsorbing pigments. Interestingly, in this case, there are microsporine-like amino acids (MAAs) that have been considered as anti-ultraviolet treads. It was found in the studies by Badeli et al. (2012) and Amirlatifi et al. (2011) that the species of Nostoc sp. FS 101 and Anaphana contain more. This significant photosynthesis continues to $7 \%$ oil values (ANOVA, $\mathrm{p}<0.05$ ).

About Microcheate sp. FS13, photosynthesis is similar but its value is less (approximately 44 micromoles oxygen per dry weight unit), which is equivalent to the ones have been obtained from Nostoc sp. FS 101 and Annapana by Amirlatifi et al. (2013) and Badeli et al. (2012).

Absorption spectra in vivo in the first days after inoculation and comparison with the days after inoculation in different concentrations indicate the effect of a time factor on the behavior of the phycobilisome system of the sample in different oil conditions at different times. In the first hours after inoculation, both samples have high-density 
spectra, in which phycobilisome system has its pigments fully, especially phycocyanin that is detectable. But then, the sample behavior changes under the influence of salinity.

The change in the behavior of the phycobilisome system is natural and is due to the metabolic fluidity of the sample, but the important issue is the time problem. In the short and medium term studies, the problem of the effect of short time (shock) on the process of changing the phycobilisome system has been evaluated.

\section{Conclusion}

The marine environment is highly susceptible to pollution by petroleum, and so, it is important to understand how the microorganisms degrade hydrocarbons. In this research, the effects of crude oil under limited light and limited salinity on physiological characterization of the cyanobacteria Fischerella sp. ISC107, Nostoc SP. ISC101, Phormidium sp. ISC108 were investigated. This study showed that growth rate and doubling time was positive for all three samples, but Phormidium sp. ISC108 had the highest rate of growth in elevated oil concentration. Photosynthetic pigments amount in different cyanobacteria grown under the limited light and limited salinity conditions showed that Phormidium sp. ISC108 had the highest amount of APC, PC, PE, Chl, Carbo and Protein. In this research salinity significantly increased the levels of carbohydrate pool and protein and photosynthetic pigments amount $(\mathrm{p}<0.01)$. Limited light eliminated induction of carbon dioxide concentration systems. Increasing oil concentrations up to $3 \%$ are significantly enhanced photosynthetic pigments amount, carbohydrate and under limited light and limited salinity but it decreased towards high concentrations $(\mathrm{p}<0.01)$. It can be concluded that the cyanobacteria can be used as a bioremediation for decomposing crude oil especially in the coastal area of the Persian Gulf and the Caspian Sea. The results of this research can be valuable for reducing the contamination which affects the fauna and flora of the marine ecosystems in our country.

Acknowledgements. The authors would like to appreciate Dr. Hossein Ebadi, Dr. Neda Soltani, Dr. Elaheh Kiaee, Dr. Fariba Amirlatifi, Mrs. Malihe Rasaee, Mrs. Ladan Baftechi and Reza Movaghari for their kind collaboration in laboratory studies.

\section{REFERENCES}

[1] Abed, R. M. M., Al-Kindi, S., Al-Kharusi, S. (2015): Diversity of bacterial communities along a petroleum contamination gradient in desert soils. - Microbial Ecology 69: 95105.

[2] Ahmadi Livani, H., Shakrovi, S., Soltani, N. (2010): Survival and growth of cyanobacteria in the conditions of salinity stress, carbon dioxide and $\mathrm{pH}$. - Islamic Azad University of Branch of Gorgan.

[3] Amirlatifi, M. (2011): Habituating cyanobacterium Anabaena sp.FS 76 and Nostoc sp. FS 77 to the conditions of acidity and alkalinity and limited light. - Master's Dissertation, Islamic Azad University, Branch of Gorgan.

[4] Amirlatifi, F., Soltani, N., Saadatmand, S., Shokravi, S. Dezfulian, M. (2013): Crude oilinduced morphological and physiological responses in Cyanobacterium microchaete tenera ISC13. - International Journal Environment Research 7(4): 1007-1014.

[5] Andersen, R. A. (2005): Algal Culturing Techniques. - Academic Press, New York. 
[6] Badeli, Z., Shokrovi, S., Derakhshanpour, J. (2012): Study of salinity modification and some physiological responses in cyanobacteria Anabena SP.FS76 under different salinity stresses. - Quarterly Journal of Plant Science 30(2): 52-59.

[7] Carrera-Martinez, D., Mateos-Sanz, A., Lopez-Rodas, V., Costas, E. (2011): Adaptation of microalgae to a gradient of continuous petroleum contamination. - Aquatic Toxicology 101: 342-350.

[8] Chekigar, Sh. (2012): Investigation of Habituating Cyanobacteria Microchaete sp.FS13 to Salinity Stress and Laboratory Adjustment Ability. - Master's Thesis, Islamic Azad University, of Branch Gorgan.

[9] Costas, E., Flores-Moya, A., Lopez-Rodas, V. (2008): Rapid adaptation of algae toextreme environments (geothermal waters) by single mutation allows "Noah's Arks" for photosynthesizers during the Neoproterozoic "snowball Earth"? - New Phytology 189: 922-932.

[10] Das, N., Chandran, P. (2011): Microbial degradation of petroleum hydrocarbon contaminants: An overview. - Biotechnology Research International 1-13.

[11] Dhull, N. P., Soni, R., Rahi, D. K., Soni, S. K. (2014): Evaluation of autotrophic and mixotrophic regimen Chlorella pyrenoidosa cells in various wastes water for its biochemical composition and biomass production. - Peer Journal PrePrints. http://dx.doi.org/10.7287/peerj.preprints, 681v1.

[12] El-Sheekh, M. M., Hamouda, R. A., Nizam, A. A. (2013): Biodegradation of crude oil by Scenedesmus obliquus and Chlorella vulgaris growing under heterotrophic conditions. International Biodeterioration and Biodegradation 82: 67-72.

[13] Gu, N., Lin, Q., Qin, G. (2012): Effect of salinity change on biomass and biochemical composition of Nannochloropsis oculata. - Journal of World Aquaculture 43: 97-105.

[14] Hamouda, R. A., Sorour, N. M., Yeheia, D. S. (2016): Biodegradation of crude oil by Anabaena oryzae, Chlorella kessleri and its consortium under mixotrophic conditions. International Biodeterioration and Biodegradation 112: 128-134.

[15] Herbert, D., Phipps, P. J., Strange, R. E. (2010): Chemical analysis of microbial cells. Methods in Microbiology 5: 209-344.

[16] Kaushik, B. D. (1987): Laboratory Methods for Blue-Green Algae. - Associated Publishing Company, New Delhi.

[17] Kiayi, E., Soltani, N., Mazeher Asadi, M., Khavaynejad, R. A., Dezfulian, M. (2013): Investigating the optimal conditions for using Cyanobacteria Synecococcus sp. ISC106 as a candidate for biodiesel production. - Journal of Aquatic Ecology 2(4): 40-51.

[18] Liu, X., Duan, S., Li, A., Xu, N., Cai, Z., Hu, Z. (2009): Effects of organic carbon sources on growth, photosynthesis, and respiration of Phaeodactylum tricornutum. - Journal of Applied Phycology 21(2): 239-246.

[19] Lowry, O. H., Rosebrough, J. N., Lewis Farr, A. L., Randall, R. J. (1951): Protein measurement with the folin phenol reagent. - Journal of Biological Chemistry 193: 26575 .

[20] Marker, A. F. H. (1972): The use of acetone and methanol in the estimation of chlorophyll in the presence of phaeophytin. - Freshwater Biology 2: 361-385.

[21] Marvizade, s. (2012): Study the adaptation of soilborn cyanobacterium to limited light, $\mathrm{pH}$ and salinity stresses situation. - MSc Thesis. Islamic Azad University, Gorgan Branch.

[22] Montagnolli, R. N., Lopes, P. R. M., Bidoia, E. D. (2015): Screening the toxicity and biodegradability of petroleum hydrocarbons by a rapid colorimetric method. - Archives of Environmental Contamination and Toxicology 68: 342-353.

[23] Pakzad, A., Masoudian, N., Shokroavi, S., Amirltaifi, H. Abbasi, B. (2011): An analysis of morphological and ultrastructural variation of two unknown strain of nostocastic density collected from paddy-fields of Gorgan, Golestan Province. - Quarterly Journal of Environmental Sciences. The First National Conference on Algal Studies in Iran 78-73. 
[24] Pittman, K. J., Estrada, B., Sigee, D. C., Dean, A. P. (2010): Using FTIR spectroscopy for rapid determination of lipid accumulation in response to nitrogen limitation in freshwater microalgae. - Bioresource Technology 101: 4499-4507.

[25] Prince, R., Gramain, A., McGenity, T. (2010): Prokaryotic Hydrocarbon Degraders. - In: Timmis, K. (ed.). Handbook of Hydrocarbon and Lipid Microbiology. - Springer, Berlin, pp: 1672-1692.

[26] Rajendran, U., Kathirvel, E., Narayanaswamy, A. (2007): Desiccation- induced in antioxidant enzymes, fatty acids and amino acids in the cyanobacterium Tolypothrix scytonemoides. - World Journal of Microbiology Biotechnology 23: 251-257.

[27] Shokravi, S., Fallahian, F., Khavarinejad, R. (2002): Nostoc sp. PTCC 1635 as biofertilizer in paddy fields:growth, heterocyst frequency and pigmentation adaptation-an ecophysiological approach. - Proceeding of the Congress on Applied Biology, Dept. Biology, Azad University, Mashhad, Iran.

[28] Shokravi, S., Soltani, N. (2011): Acclimation of the Hapalosiphon sp. FS 56 (cyanobacteria) to combination effects of dissolved inorganic carbon and $\mathrm{pH}$ at extremely limited irradiance. - International Journal of Algae 13(4): 379-391.

[29] Shruthi, M. S., Rajashekhar, M. (2014): Effect of salinity and growth phase on the biochemical composition of two diatom species isolated from estuarine waters near Mangalore, West Coast of India. - International Journal of Advance Life science 7(1): 135-142.

[30] Soltani, N., Khavarinejad, R. A, Tabatabaie, M., Shokravi, S. Valiente, E. F. (2006): Variation of Nitrogenase Activity, photosynthesis and pigmentation of cyanobacteria Fischerellaambigua strain FS18 under different irradiance and pH. - World Journal of Microbiol Biotechnology 22(6): 571-577.

[31] Soltani, N., Khavarinejad, R. A., Tabatabaei Yazdi, M., Shokravi, Sh. (2007): Growth and metabolic Feature of cyanobacteria Fischerella sp. FS18 in different combined nitrogen sources. - Iranian Journal of Science 18(2): 123-128.

[32] Soltani, N., Siahbalaie, R., Shokravi, S. (2011): Taxonomical characterization of Fischerella sp. FS18 - A multidisciplinary approach. - International journal on Algae 1(9): 48-55.

[33] Stal, L. J. (1995): Physiological ecology of cyanobacteria in microbial mats and other communities. - New Phytologist Journal 131: 1-32.

[34] Tamkini, M., Abolfathi, A. A., Shokravi, S. (2015): Photobiochemistry of photosynthetic pigments of edaphic Cyanobacterium anabaena sp. FS76 under the combination effect of irradiance and carbon dioxide concentrations. - International Journal of Scientific and Engineering Research 6(2): 386-394. 